\title{
IMPLICAÇÕES DE PROGRAMAS DE ENXUGAMENTO PARA EX-TRABALHADORES DE EMPRESAS ESTATAIS
}

\author{
Suzana da Rosa Tolfo \\ Maria Chalfin Coutinho \\ Universidade Federal de Santa Catarina, Florianopólis, Brasil
}

RESUMO: O contexto produtivo brasileiro passou por uma série de transformações nas últimas décadas do século XX. Dentre elas está a reforma do Estado, que impulsionou programas de privatização e enxugamento de empresas estatais, com repercussões para a sociedade e os trabalhadores envolvidos. Para caracterizar esse fenômeno, foi realizado um estudo comparativo de casos sobre as implicações psicossociais de programas de reestruturação e privatização para ex-trabalhadores de duas empresas (energia elétrica e telecomunicações). Trata-se de pesquisa de caráter exploratóriodescritivo, de natureza qualitativa. As informações foram coletadas por meio de entrevistas semi-estruturadas com extrabalhadores aposentados ou demitidos. Foi realizada a análise dos conteúdos das entrevistas. Os sujeitos, mesmo evidenciando a compreensão dos aspectos conjunturais determinantes dos processos de privatização, ressentiram-se com a quebra do contrato formal e psicológico estabelecido anteriormente com as empresas. As mudanças e os desligamentos implicaram em intenso sofrimento psicológico e alterações na vida pessoal e profissional dos entrevistados. PALAVRAS-CHAVE: Reestruturação; privatização; ex-trabalhadores; empresas estatais.

\section{IMPLICATIONS OF LAYOFF PROGRAMS FOR EX-WORKERS OF STATE COMPANIES}

ABSTRACT: The Brazilian productive context has gone through a series of alterations in the last decades of the $20^{\text {th }}$ century. Among them there is the State reformation, which stimulated privatization programs and layoffs of state companies, with reflections to the society and the workers involved in the process. A comparative study of cases about the psychosocial implications of restructuring and privatization programs for ex-workers of two companies (electrical energy and telecommunications) was done to describe this phenomenon. It's a qualitative, exploratory-descriptive research. Information was collected through semi-structured interviews with retired or fired workers. The content of the interviews' had been analyzed. The subjects, even showing comprehension about the conjectural aspects of the privatization process, suffered the consequences of the formal and psychological contract's break established before with the companies. The changes and the detachment implied in intense psychological suffering and changes in personal and professional life of the professionals interviewed.

KEYWORDS: Restructuring; privatization; ex-workers; state companies.

Nas últimas décadas do século $\mathrm{XX}$, grandes transformações puderam ser evidenciadas na ordem econômica, social e política, em diferentes países. No contexto produtivo assistiu-se a um quadro de crescente competitividade, paralelamente ao decréscimo das taxas de lucratividade. Diante deste contexto, a recuperação de padrões anteriores de acumulação do capital foi buscada através de diferentes processos de reestruturação produtiva.

Tais mudanças atingem os países industrializados de diferentes formas. Segundo Laranjeira (1998, p. 164), nos países periféricos a reestruturação produtiva apresenta algumas características peculiares, ao assumir “... um caráter defensivo e de controvérsia política, já que envolve soluções que implicam a transferência total ou parcial de bens públicos, em muitos casos para o capital estrangeiro." Especificamente no caso brasileiro, a partir dos anos 1990, foi observado intenso processo de enxugamento da esfera estatal, centrado na proposta de privatização de empresas atuantes nos setores estratégicos de serviços, tais como tele- comunicações, energia elétrica e bancos estatais. Este processo constituiu-se como a estratégia central do programa de reforma do Estado, que integra a política neoliberal imposta por organismos financeiros internacionais, aos países do chamado terceiro mundo (Jesus, 1998).

A privatização foi uma prática generalizada na reestruturação de empresas de energia elétrica e telecomunicações, focos deste estudo. Ao caracterizar o desenvolvimento deste último setor no Brasil, Dutra, Hipólito e Silva (2000) observam o quanto foi, desde o início, marcado pela forte atuação dos governos, envolvendo a propriedade de companhias telefônicas ou a regulamentação de suas atividades; o mesmo ocorreu com o setor elétrico. No Brasil, segundo Fischer, Carvalho Filho e Cavalcanti (1998), as práticas do governo federal de utilizar empresas públicas como instrumentos de políticas de estabilização para o controle de preços e tetos para investimentos, com o objetivo de conter a inflação, foram utilizadas como justificativas para a necessidade de privatizar. 
Tanto o setor de energia elétrica, como o setor de telecomunicações brasileiro seguiu, desta forma, as mudanças ocorridas no mundo do trabalho. Correia e Moraes (1998) afirmam que fatores como abertura de mercado, privatização das empresas operadoras, intenso desenvolvimento tecnológico, desconhecimento dos entrantes potenciais, grande expansão e diversificação do mercado, assim como a necessidade de vultosos recursos financeiros para investimentos na expansão, pesquisa e desenvolvimento tecnológico e de serviços, alteraram completamente o cenário existente até poucos anos atrás. Houve um forte impulso aos programas de enxugamento e privatização de empresas estatais, com repercussões profundas para o conjunto da sociedade e, em particular, para os trabalhadores envolvidos.

Dentro do contexto acima descrito, foi desenvolvida esta investigação sobre as vivências de ex-trabalhadores de duas empresas estatais, uma do setor elétrico e outra do setor de telecomunicações, que passaram por programas de enxugamentos e privatização. O presente artigo apresenta e discute as vivências psicossociais destes trabalhadores.

\section{Método}

A investigação foi realizada por meio de estudo comparativo de casos, de natureza predominantemente qualitativa, realizado com ex-trabalhadores de duas grandes estatais (ELÉTRICA e TELEFONIA - nomes fictícios), com sede na região da Grande Florianópolis, nas quais foram implementados amplos programas de enxugamento de pessoal, com vistas à privatização durante os anos 90 , do século XX. O principal instrumento para coleta de informações foi a entrevista semi-estruturada. Foram entrevistados 20 ex-trabalhadores, sendo 10 de cada empresa. Cabe resssaltar que enquanto os entrevistados egressos da ELÉTRICA não permaneceram na empresa, alguns dos ex-empregados da TELEFONIA saíram em diferentes períodos de enxugamento de pessoal ou permaneceram trabalhando para a mesma como terceirizados.

Os sujeitos foram contatados por telefone e as entrevistas foram realizadas em locais escolhidos por eles, em geral suas residências. Após os esclarecimentos, era solicitada sua autorização para participar na pesquisa e para a gravação da entrevista, pautando-se nos parâmetros éticos para a pesquisa com seres humanos estabelecidos na resolução 196/96 do Conselho Nacional de Saúde. Embora as entrevistas seguissem roteiros previamente estabelecidos, havia flexibilidade para que os participantes explicitassem outros conteúdos que avaliassem como importantes e relacionados com o fenômeno sob investigação.

Os conteúdos das entrevistas (gravadas e, posteriormente, transcritas) foram organizados em categorias temáticas, o que possibilitou sua análise e interpretação, tendo como referência o método de análise qualitativa de conteúdo baseado em Bardin (1977). Os resultados de cada estudo de caso foram organizados nas seguintes categorias temáticas: caracterização da empresa e dos entrevistados, transformações ocorridas na empresa e implicações para os trabalhadores (incluindo visão dos entrevistados sobre as mudanças e os desligamentos).

\section{Estudo de casos com ex-trabalhadores de uma empresa de energia elétrica}

\section{A empresa e os ex-trabalhadores entrevistados}

Desde os anos 80, do século passado, o sistema brasileiro de energia elétrica, caracterizado pela presença de grandes empresas estatais, passou a ser reordenado. Entretanto, as iniciativas de privatização das empresas do setor são aceleradas nos anos 90 :

As empresas integrantes da holding foram orientadas no sentido de buscar parceiros privados para dar andamento a projetos que estavam paralisados por falta de recursos financeiros. Também surgiram iniciativas para reorganização interna dessas empresas, a partir da redefinição de suas atividades essenciais e da redução do número de colaboradores. As cisões se tornaram freqüentes, reordenando especialmente os setores de geração e transmissão (Santos \& Reis, 2002, p. 202).

Neste contexto se situa a empresa onde trabalhavam os participantes do presente estudo de caso. Trata-se de uma empresa estatal federal de energia elétrica, cuja sede localiza-se na região da Grande Florianópolis. Fundada em 1968, a ELÉTRICA passou por um intenso processo de enxugamento durante os anos 1990, culminando com sua cisão em 1997. A estatal foi, então, dividida em duas: uma responsável pelas atividades de transmissão energética, mantida como estatal federal, e outra atuando na geração de energia, privatizada em 1998.

Desde a sua fundação até 1989 , quando foi efetivado um grande contingente de trabalhadores, a ELÉTRICA ampliou consideravelmente o seu quadro de pessoal, que atingiu, neste ano, quase 6.000 trabalhadores. Os desligamentos iniciaram em 1990, seja através de programas de demissão incentivada ou pela aposentadoria, ou mesmo com cisão, que levou parte dos trabalhadores para a geradora, posteriormente privatizada. Com isto, houve uma forte redução do número de funcionários e a empresa atingiu um quadro de trabalhadores de cerca de 1.200 empregados em 2001. Posteriormente, ${ }^{1}$ com a revisão da política de privatização da empresa, incluindo a abertura para a retomada de atividades de geração de energia, os concursos e as admissões de novos funcionários são retomados.

Neste estudo foram entrevistados 10 trabalhadores egressos (cinco homens e cinco mulheres) com idades entre 48 
e 58 anos, na época da entrevista. Todos tinham menos de 50 anos quando foram desligados, incluindo três com menos de 40 anos. Suas trajetórias na empresa foram longas, trabalharam lá por no mínimo 10 anos, sendo que três deles permaneceram na organização por mais de 20 anos. Todos apresentam um grau alto de escolaridade: metade tem formação superior (um com mestrado), os outros completaram o ensino secundário. Tal como em outros estudos realizados com trabalhadores da mesma empresa, ${ }^{2}$ os entrevistados relatam um forte vínculo e satisfação em trabalhar na ELÉTRICA.

Os entrevistados foram desligados da empresa depois dos anos 90, seis saíram entre os anos de 1990 e 1995 e quatro entre 1996 e 2000, dos quais apenas um saiu após a cisão. Os desligamentos acontecerem de diferentes formas: quatro se aposentaram, cinco aderiram a planos de demissão incentivada (PDI), embora dois destes relatem só terem aderido após a demissão, e uma foi demitida.

\section{Transformações na empresa e implicações para os trabalhadores}

Mudanças. No período de reestruturação da empresa, os entrevistados destacam o aumento da influência política, desviando a empresa de suas estratégias de desenvolvimento, com a paralisação dos investimentos e das obras. "A gerência de interesses políticos locais, prejudicou a estratégia como empresa de desenvolvimento da região sul que ela se propunha a realizar" (E. 4).

Alguns entrevistados relatam sua compreensão de que a reestruturação, implementada na empresa pelo governo federal, fazia parte de um contexto maior de implantação de reformas neoliberais, não só brasileiro, como mundial. Como expressa um participante, a responsabilidade foi do presidente da república, pois “.... ele $e^{3}$ abaixou a cabeça muito, muito, muito, muito, pra essas forças de pressão, de banqueiros internacionais e tudo, aí se desfez de várias empresas assim, ... rapidamente, a preço de bana$n a "$ (Е. 10).

Para a maior parte dos entrevistados as mudanças visavam principalmente redução de pessoal e de custos e foram impostas, não tendo havido possibilidade de se opor a elas. "E isso veio como determinação mesmo que não adianta nem tentar discutir" (E. 2).

Mesmo após anos, alguns ainda se sentiam incapazes de compreender as razões para todo o processo implementado na ELÉTRICA. “... empresas altamente lucrativas... numa canetada foram acabadas... isso é de um surrealismo que não dá pra entender..." (E. 10).

Os boatos, particularmente as listas com os nomes dos funcionários a serem demitidos, constituíram-se em um forte elemento de pressão, gerando um clima de tensão e insegurança. “... sempre havia aquela boataria no ar, né: 'Vai ter mais uma leva! Vai ter mais uma lista! Vai ter mais demissões!"' (E. 1). A ansiedade, associada ao medo do desemprego e às crises econômicas, foi identificada por Seligmann-Silva (1994). A autora também observou nestes momentos de crise, rumores sobre listas de demissão.

Alguns entrevistados, mesmo concordando que a empresa tinha um contingente de pessoal excessivo, relatam dificuldades em aceitar os enxugamentos; questionando o modo como foram feitos, seja por sua extensão ou em função dos critérios utilizados, em geral políticos e não relativos à competência no trabalho.

Outros participantes mostraram-se totalmente contrários às mudanças ocorridas e apontavam outras soluções possíveis para os problemas da empresa, que não a direcionassem para a privatização, tal como ocorreu em outras empresas do setor elétrico. "Na verdade a ELÉTRICA serviu de... foi a teste... e foi fácil, não houve resistência..." (E. 10).

A maioria dos entrevistados relatou dor e sofrimento diante dos acontecimentos. O relacionamento entre colegas foi bastante prejudicado, principalmente com as chefias, encarregadas de demitir.

\footnotetext{
"Acabou, acabou com o relacionamento, todo mundo desconfiava do outro.” (E. 8).

“... Simplesmente de colocar o funcionário numa lista de demissão sem se importar com a condição dele, com salário, com capacidade profissional, com família, com filhos...” (E. 2).
}

Outro aspecto bastante evidenciado diz respeito ao clima de terror criado na empresa. O medo do desemprego apareceu como um elemento aterrorizante para os entrevistados: "Pô, ficar sem emprego, né, sem um salário, com mais de 40 anos'. Imagina!" (E. 6). Este tipo de referência aos programas de enxugamento também foi observado em outros estudos empíricos. Lima (2000), por exemplo, investigou funcionários de um banco estatal no qual foram implantados Programas de Demissão Voluntária. Tal processo foi vivenciado como um período de terrorismo pelos funcionários. Mas este sentimento também emergia diante de fatos, aparentemente, sem relevância, como a foto do presidente da república: “. . . houve aquele clima de terrorismo ... aí eles colocaram uma foto enorme do Collor ${ }^{4}$ bem na catraca pra ti ver todo dia que tu passasse ali..." (E. 8).

O clima de terrorismo estimulou a competitividade e o individualismo, o que segundo uma entrevistada seria revelador do verdadeiro caráter de cada um: “... o vernizinho da educação, da formação, dos princípios, dos valores são nas horas, nos momentos extremos... Porque era assim jogando colega contra colega, humilhações assim..." (E. 10). O clima vivenciado pelos trabalhadores dificultaria a construção de narrativas coerentes de vida, abrindo espaço para a emergência do que Sennet (2002) considera como uma corrosão do caráter. 
Acostumados com uma situação anterior de estabilidade, era difícil lidar com a incerteza, tanto em relação ao futuro da empresa, como em relação ao seu próprio futuro pessoal e familiar. “... amanhã tu não sabe se vai ter condições de pagar o teu condomínio, a tua água, a tua luz, o estudo dos teus filhos..." (E. 8).

Em seu estudo com egressos de um banco estatal, Segnini (2001) observou que, embora o mercado de trabalho brasileiro não tenha estabelecido uma situação de emprego formal com direitos generalizados, como aconteceu em países desenvolvidos, os setores estatais podem ser considerados como exceções, visto que seus empregados tiveram acesso a garantias e direitos sociais. Sendo assim, a autora compreende que estes sujeitos estariam vivenciando processos de desfiliação e vulnerabilidade social, tal como foi observado nos participantes da presente pesquisa. Outros autores também referem a maior vulnerabilização dos indivíduos, excluídos por processos de reestruturação em empresas (Gomes, 2002; Kovács, 2003).

Entre estratégias de enfrentamento das vivências de sofrimento, alguns dizem terem procurado esquecer. Para outros tal esquecimento não foi possível, pois foram afetados pelo processo, como expressam as seguintes falas:

“... eu não sei porque eu apaguei muita coisa assim da minha memória, porque as demissões foram uma coisa muito ruim assim pro pessoal...” (E. 6).

“... foi traumatizante pra todo mundo, pro empregado em si, pros familiares, amigos, pra comunidade em geral" (E. 1).

Ao investigar empresas que implantaram programas de demissão incentivada, Caldas (2000) também identificou as repercussões negativas destes programas tanto para os desligados e como para os remanescentes. ${ }^{5}$

Alguns entrevistados revelam sentimentos de nulidade e vazio associados à percepção de que foram descartados e não tiveram sua capacidade profissional respeitada. Tais sentimentos abalaram profundamente sua saúde física e mental, tal com foi apontado por Seligmann-Silva (1994), com implicações para a vida familiar dos mais afetados, como pode ser evidenciado em algumas falas dos entrevistados:

“... não só aconteceu comigo como vários amigos meus tiveram sérios problemas em casa, familiares, com tudo, né, problemas de saúde inclusive...” (Е. 2).

“... vivia bebendo, todo mundo saia da empresa e ia pro bar.” (E. 8).

Desligamentos. A atuação da administração durante o processo de enxugamento foi bastante criticada, particularmente pela forma como as pessoas foram pressionadas a se desligarem da empresa. Neste sentido, a conduta das chefias foi muito questionada pelos participantes.
“... foi uma maneira assim muito terrível de fazerem certas... chefias de pressionarem os seus funcionários pra fazer com que eles pedissem demissão...” (Е. 9).

Outro aspecto negativo dos desligamentos está relacionado à forma repentina como algumas pessoas eram informadas sobre a sua saída da empresa, incluindo o caso de uma entrevistada que relata ter sido chamada, durante uma licença para tratamento de saúde, e demitida, só então teria aderido ao PDI.

Através dos relatos, fica claro que não havia procedimentos uniformes, cada trabalhador era avisado de uma maneira. Com relação aos critérios adotados para o desligamento, a maior parte dos entrevistados compartilha a opinião de que a competência do trabalhador não era levada em consideração pela empresa.

"E não existia critério que fosse considerada a capacidade profissional, as especializações do profissional, o lado social do profissional ou da própria empresa, isso aí não foi nada levado em consideração" (E. 2).

Diante da falta de clareza com relação aos critérios adotados, alguns participantes buscavam estabelecer suas próprias explicações para o que viam acontecer no dia-adia de demissões da empresa. Uma hipótese levantada é de que cada chefia fazia os cortes de pessoal conforme critérios pessoais, tais como: amizade, competência técnica, motivação etc. A influência política foi considerada como um fator importante nas decisões tomadas pelos administradores.

“... as pessoas que sabiam que tavam na lista corriam pro político... e o político mandava um pedido pro presidente da ELÉTRICA e saía” (E. 10).

Caldas (2000) descreve uma série de fatores moderadores dos efeitos negativos da demissão, entre eles destaca a forma como são feitos os cortes, tendo em vista “... a noção de justiça que as pessoas vêem no processo, os critérios usados e, por fim, o respeito e a dignidade [itálicos do autor] que a organização mostra em relação aos desligados" (p. 166). As falas dos entrevistados evidenciam a ausência critérios que pudessem minimizar os efeitos negativos dos enxugamentos.

Ainda que o momento do desligamento tenha sido vivido pela maioria com intenso sofrimento psicológico, alguns entrevistados puderam lidar com a situação de forma menos dolorosa. Ter outras possibilidades de atuação profissional e/ou outros projetos profissionais foram fatores facilitadores para a saída da empresa, como o caso da entrevistada que já atuava em outra empresa como nutricionista, ou o caso do participante que aproveitou o dinheiro recebido para colocar em prática o projeto de abrir uma empresa. 
Para outros o desligamento suscitou sentimentos de insegurança, uma vez que não se sentiam preparados para se re-inserirem no mercado de trabalho:

“... eu me dediquei à ELÉTRICA... eu não tinha negócio paralelo, então quando saí é como tu ir na rua assim ó: 'Eu tô com dinheiro, mas o que que eu faço com ele?’” (E. 5).

Ao investigar as trajetórias de ex-empregados do setor elétrico brasileiro, Etcheverry $(2003)^{6}$ classificou estas trajetórias em duas grandes categorias: os que resistiram à separação da empresa e os que não resistiram a esta separação. Os primeiros tinham uma forte identificação com a empresa, não pensavam em se desligar dela. Os que não resistiram tinham um projeto profissional alternativo ou valorizavam o espírito empreendedor e optaram pela vida autônoma. Também no presente estudo foi possível identificar os dois tipos de trajetória em relação ao desligamento da empresa.

Mesmo quem relata ter vivenciado o processo de maneira tranquiila, lamenta as perdas pela saída da empresa: da remuneração, dos benefícios ou mesmo da própria atividade profissional:

“... eu perdi essa assistência toda e outra que eu acho que não tava na hora de eu me aposentar, eu tinha saúde ainda pra continuar trabalhando” (E. 3).

Para as mulheres o desligamento significou ter de se adaptar a viver apenas em função de atividades domésticas. "O que que eu ia fazer? Não podia fazer nada, né, aceitar a situação, voltar a ser dona de casa, mas pra gente que sempre acostumou a trabalhar fora foi muito dificil' (E. 6).

Um participante, integrante de uma equipe que fazia os cálculos rescisórios dos PDIs, cuja a chefia prometera não incluí-lo nas listas de demissão, refere o desligamento como “... um baque muito grande... E depois por uma questão de raiva mesmo, por saber que a coisa tava sendo tratada daquela maneira, inclusive com mentira" (E. 2). Mesmo tendo colaborado com a gestão dos programas de enxugamento, este trabalhador não foi poupado.

Ao contribuir para as práticas implementadas, o entrevistado acima, do mesmo modo que outros trabalhadores - em especial as chefias, ao pressionarem para adesão aos programas de desligamento - teriam sido levados a agir como "colaboradores com o mal", no sentido apontado por Dejours (1999). Para este autor, os modernos sistemas de gestão empresarial são baseados “.... na utilização metódica da ameaça e numa estratégia eficaz de distorção da comunicação" (p. 138-139). Desta forma, as "pessoas de bem" são levadas a colaborar com práticas que elas reprovariam, tais como a seleção dos excluídos, incluindo-os em listas de demissão, bem como outras práticas consideradas injustas e/ou ilegais, etc.

\section{Estudo de caso com ex-trabalhadores de uma empresa do setor de telecomunicações}

A empresa e os ex-trabalhadores entrevistados

A TELEFONIA teve a sua origem na Companhia Telefônica CTC, inaugurada em setembro de 1930. Em julho de 1969, o Governo do Estado de Santa Catarina, adquiriu a CTC e constituiu a sua empresa estatal: a Companhia C de Telecomunicações-COTESC. Em 1974, a COTESC foi substituída pela TELEFONIA, que se tornou uma das primeiras subsidiárias da Telebrás. Com o avanço tecnológico e os investimentos na qualificação dos técnicos, a empresa era, em 1978, a segunda do sistema Telebrás.

A privatização da empresa ocorreu em julho de 1998, quando houve a cisão em todo o sistema Telebrás, que era constituído de 12 holdings. Esse processo representou a transferência total, à iniciativa privada, do controle acionário das empresas de telefonia fixa e de longa distância, bem como das empresas de telefonia celular.

A TELEFONIA possuía em torno de 2.300 funcionários em meados da década de 1990, ao passo que esse número foi reduzido à metade no início do século XXI. Devido às mudanças ocasionadas pela privatização, a gestão adotou como uma das suas estratégias o incentivo aos empregados com mais tempo de serviço na empresa para que aderissem ao Plano de Demissão Incentivada ou à aposentadoria. Isso parece ter ocorrido devido ao objetivo da gestão da empresa de manter uma mão de obra mais barata e reduzir o número de funcionários.

Tendo em vista o interesse em compreender as vivências de sujeitos em face a contextos de enxugamento, foi realizado este estudo, cujos participantes foram 10 pessoas, sendo seis homens e quatro mulheres, com idades entre 38 e 51 anos de idade. Quanto à escolaridade, quatro deles possuía $3^{\circ}$ grau completo e quatro cursaram o $2^{\circ}$ grau técnico, já o tempo de serviço variou de 10 a 25 anos de trabalho. Com base na caracterização, é possível verificar que os sujeitos apresentam uma média de idade de 44 anos e 18 anos de serviço. Estes dados demonstram que, em sua maioria, são profissionais que dedicaram muitos anos de trabalho à empresa e estavam em uma idade de plena capacidade produtiva. Quanto à escolaridade, predomina o nível superior (completo ou incompleto), o que reflete a ênfase que a estatal concedia à escolarização dos seus empregados.

\section{Transformações na empresa e implicações para os trabalhadores}

Mudanças. Um dos aspectos mais citados pelos participantes como representativo das mudanças na organização foi a deterioração do clima organizacional em decorrência do aumento das cobranças por produtividade, desempenho individual ou demissões, o que gerou insegurança, 
medo e pressão nos trabalhadores. Segundo dois entrevistados, cujas falas são representativas dos seus pares, aumentou o: "Estresse, cobrança, desorganização" (E. 15), e o "Clima organizacional (ficou) tenso, com o início das demissões" (E. 8). Os desgastes sobre os indivíduos submetidos a situações de grandes mudanças organizacionais são plenamente identificáveis nas falas apresentadas.

Para Echeverria (apud Seligmann-Silva, 1994, p. 257) o sofrimento psíquico em situações de mudança organizacional tem sua fonte nas alterações nos processos de laborar e na eminência de perda de emprego. As transformações dos processos laborais estão relacionadas à busca constante, por parte das organizações, pelo aumento da produtividade que submete os trabalhadores a certas condições objetivas e subjetivas de trabalho.

Um número expressivo de entrevistados referiu-se às mudanças como um processo mal conduzido, que objetivava primordialmente o lucro, contemplando o interesse de grupos restritos e que pode ser expresso como um: "Processo político com interesse de grupos nacionais e internacionais" (E. 8). Verifica-se que, tal qual os participantes do setor elétrico, os entrevistados da pesquisa no setor de telecomunicações compreendem que as mudanças na empresa faziam parte de um contexto maior e que não havia possibilidades de interferência para cessar a mudança. A abertura do mercado brasileiro e a participação de grandes empresas multinacionais da compra das empresas estatais foram cercadas de um trabalho de marketing que mostrava somente aspectos positivos nas mudanças. Os "bastidores" das negociações foram, em parte, relatados bem mais tarde e discussões sobre acordos e "negociatas" mantêm personagens centrais em evidência na mídia.

Os participantes referem mudanças nos processos de trabalho após o início do processo de privatização, de modo que cinco dos entrevistados relatam que houve aumento da carga e limitação nas atividades realizadas pelos colaboradores. Quanto ao aumento em termos da quantidade, os ex-trabalhadores verificaram que a: "Carga de trabalho aumentou muito, sem pessoal qualificado, a empresa perdeu qualidade nos serviços" (E. 14), e "Maior exigência no trabalho, inclusive fora do expediente normal" (E. 18).

O aumento do trabalho a ser realizado tem sido freqüente nesse tipo de mudança, já que as tarefas continuaram as mesmas ou até aumentaram enquanto o número de trabalhadores para realizá-las diminui. O objetivo organizacional declarado para o corte de empregados é o de melhorar o desempenho da organização, mas Caldas (2000) salienta que os resultados dos cortes têm ficado aquém do esperado pelas organizações, fazendo, inclusive com que muitas delas tenham efeitos negativos não avaliados.
Em relação aos limites nas atividades realizadas, há exemplos que chamam a atenção para o esvaziamento das funções, conforme o seguinte relato:

Antes da mudança o meu trabalho priorizava o planejamento, as ações de marketing e fundamentalmente estava focado em projetos que tinham relação com os níveis tático e estratégico da organização. Após a mudança a filial de Santa Catarina perdeu importância no cenário das telecomunicações. $O$ tático e o estratégico foram deslocados para Brasília, restando aos empregados em Santa Catarina, preocupar-se com ações operacionais (E. 19).

A perda de funções estratégicas pela empresa local também é citada como uma nova condição que precariza o trabalho no que tange a possibilidade do individuo planejar, entender e interferir naquilo que faz. Alguns entrevistados ressaltam que houve grande desinformação e desorientação a respeito das mudanças que ocorreriam na empresa como um todo e, principalmente, no processo de trabalho dos colaboradores, de modo que: "Foi surpresa. O próprio ritmo de trabalho foi afetado. Os funcionários ficaram meio desorientados devido às incertezas. Não houve um trabalho social digno de uma empresa do porte da Telefonia" (E. 11).

As incertezas foram enfaticamente salientadas pelos entrevistados como significativas de grandes mudanças geradas e que refletem o rompimento do contrato psicológico vigente até então entre a organização e os trabalhadores. A mesma percepção de desorientação e quebra de contrato foi verificada no caso dos eletricitários. Conforme Wetzel (2001), o contrato psicológico é o contrato não formal estabelecido entre empregados e empregador no que tange a direitos e deveres mútuos; diz respeito a crenças e percepções dos funcionários dos termos mútuos implicitamente construídos. Quando uma das partes percebe que o contrato foi rompido evidencia-se a redução de benefícios e um novo equilíbrio tende a ser buscado; assim o funcionário pode experimentar-se desobrigado a cumprir certas obrigações organizacionais e o fluxo de comunicação, a cooperação, o desempenho e a tomada de decisões podem ser prejudicados.

Com base nos conteúdos relativos às mudanças, verifica-se que elas foram de diversas ordens e geraram implicações também diversas. As principais delas foram o estresse, problemas no clima organizacional, quebra de contrato psicológico e sobrecarga de trabalho.

Desligamentos. Ao ser indagado sobre o processo de desligamento, decorrente da privatização, a maioria dos participantes citou-o como gerador de grande desgaste físico e mental. De acordo com alguns foi "pânico total" (E. 12). Esses conteúdos vão ao encontro do que trata a literatura sobre a temática, quando Seligmann-Silva (1994) salienta que as mudanças de ordem econômica (e também 
do contrato formal ou informal de trabalho) ocasionam sofrimento psíquico.

Autores como Segnini (2001), Gomes (2002) e Kovács (2003) salientam que os indivíduos tornam-se mais vulneráveis com a exclusão em decorrência de processos de reestruturação produtiva nas empresas. Para a primeira das três pesquisadoras, os setores estatais são emblemáticos neste sentido em razão de que as garantias e direitos sociais dos seus empregados eram positivamente diferenciados. Preocupações com a perda de direitos diferenciados, em comparação com outros trabalhadores brasileiros, foram encontradas nos dois estudos analisados neste artigo.

A situação particular do desemprego faz com que grande parte dos entrevistados desempregados e que aderiram ao PDI afirme a importância de trabalhar com vínculo empregatício pela sua ausência. Este entendimento aparece em conteúdos como os apresentados por dois entrevistados e que são representativos dos pares: "Deixar de trabalhar é como morrer... No trabalho me sentia eterno, quando fui demitido me senti perdido" (E. 14), e "Quem não tem emprego não é ninguém" (E. 13).

Os sentimentos de falta de objetivos, medo, finitude e anomia, decorrentes do desemprego são plenamente justificáveis, pois a relação entre trabalho e emprego ainda é muito forte na nossa sociedade atual. De acordo com Caldas (2000) os significados que construímos estão, em grande parte, referenciados a uma organização ou um papel organizacional. Sendo assim, "na medida em que às vezes construímos o que somos através de o que [itálicos do autor] fazemos, a perda do emprego pode significar o sentimento de 'dissolução' ou de 'mutilação' de aspectos elementares do nosso eu" (Caldas, 2000, p. 8).

Em terceiro lugar está a referência de que houve uma traição pela empresa, que consideravam como uma mãe ou como uma segunda família. Isso ocasionou sofrimento e sentimento de abandono que pode ser evidenciado na fala: "Saía da minha família e ia pra outra [a empresa]" (E. 13). De acordo com Seligmann-Silva (1994) e Caldas (2000) na situação de dependência é muito comum que os trabalhadores emprestem uma figura parental à empresa, onde a perda do emprego, ou de seus benefícios, gera sentimentos de perplexidade e mágoa, como explicitado nos conteúdos verbalizados pelos ex-trabalhadores. A identificação da empresa como uma família pressupõe relações de apoio mútuo e afetos.

Os relatos referentes à falta de clareza sobre o processo de demissões foram predominantes entre os participantes. Foi avaliado como: "Pouco transparente, promessas frustradas, não houve clareza dos critérios de escolha dos que seriam demitidos ou não" (E. 6). A maior parte deles salientou que a empresa preocupou-se em cortar pessoal, sem estabelecer outros critérios que não os econômicos. Predomina o entendimento da falta de preparação da maio- ria dos trabalhadores no processo de demissão e que vai ao encontro de resultados de outras pesquisas que apontam o enxugamento de pessoal como uma prática que se tornou usual nas organizações, para fazer frente à necessidade de responder às demandas do mercado e aumentar a competitividade. Verifica-se uma prática que privilegia “... a ação organizacional focada na redução de despesas, geralmente por meio de cortes de pessoal e, às vezes, por meio da mudança de elementos da estrutura e do funcionamento organizacionais" (Caldas, 2000, p. 30). De acordo com os últimos relatos, a empresa priorizou o enxugamento para a redução de custos, sem explicitar claramente as estratégias para a mudança.

No que tange à falta de critérios ou de clareza explicitadas nos relatos, é possível afirmar que a desinformação permeou o processo de demissão na empresa. Para Seligmann-Silva (1994) as empresas em processo de demissão podem utilizar a desinformação como uma estratégia de manipulação de seus empregados com vistas a um aumento da produtividade, o que a autora intitula de 'máscaras de constituição mista'. Todavia, pode acontecer o inverso: a desinformação pode gerar efeitos negativos na produtividade em função da tensão e, conseqüentemente, do desgaste pelo qual passam os trabalhadores. A falta tanto de critérios, quanto de clareza na gestão dos desligamentos foi comum à privatização da Elétrica e da Telefonia.

\section{Considerações Finais}

A mundialização da economia e a predominância do sistema capitalista e neoliberal foram plenamente identificadas pelos participantes desta pesquisa como elementos constituintes dos processos de privatização ocorridos nas duas empresas estudadas. O Estado foi se desvencilhando de atuar em setores até mesmo estratégicos para a sociedade e passando, para a iniciativa privada, empresas que anteriormente estavam sob a sua gestão. O objetivo, segundo o governo, foi injetar capital e melhorar serviços que, até então, não estavam satisfazendo grande parcela da sociedade.

Inicialmente a população, face à propaganda maciça da mídia em favor das privatizações, adotou o ideário de um processo necessário e irreversível, que implementaria melhorias no atendimento, na qualidade e no preço dos serviços. Tal crença não emerge no discurso daqueles que vivenciaram programas de enxugamento, identificando suas experiências como resultado de políticas econômicas impostas por governos submetidos a organismos financeiros internacionais e interesses econômicos.

Os eletricitários entrevistados apontaram o período de mudanças como de acirramento de problemas anteriores, por exemplo, a influência política nas decisões dos gestores da organização. Já os trabalhadores de Telefonia destacam as mudanças no conteúdo das tarefas, redução da comple- 
xidade das mesmas e aumento da carga de trabalho. Neste sentido, cabe ressaltar que enquanto a Elétrica permaneceu com parte estatal e outra parte foi privatizada, a Telefonia foi totalmente privatizada. Como decorrência os eletricitários destacam o processo de mudanças, enquanto os telefônicos ressaltam mais os eventos relativos à privatização e suas consequiências.

Mesmo evidenciando sua compreensão a respeito dos determinantes mais amplos das mudanças, os entrevistados revelam dificuldades para entender e aceitar perdas decorrentes do rompimento do contrato tanto formal, como psicológico estabelecido com as empresas. As perdas formais foram associadas aos benefícios e à estabilidade no emprego, gerando maior vulnerabilidade social. Já o rompimento do contrato psicológico foi potencializado na medida em que os participantes tinham forte vínculo e orgulho de fazer parte da empresa, percebida como uma família (ou mãe).

As mudanças e os desligamentos geraram um sofrimento psicológico, vivenciado de forma individualizada pelos entrevistados. A psicopatologia da recessão (Seligmann-Silva, 1994), caracteriza-se, nos entrevistados, pelo predomínio da apatia, ou seja, a resposta resignada de defesa a situações de frustração prolongada. As pressões exercidas pelos gestores para o desligamento dificultaram o desenvolvimento de estratégias coletivas de defesa pelos trabalhadores (Dejours, 1999). A definição de ações coletivas, têm um papel essencial na estruturação e na construção dos coletivos de trabalho e o desmantelamento dessas possibilidades propicia a culpabilização individual dos sujeitos pelos acontecimentos.

Em relação à desinformação nos processos de privatização, Donahue (1992) defende uma posição mais ética, na qual seria politicamente prudente e louvavelmente humano tomar providências para amortecer o choque da privatização para os trabalhadores. Considera que uma competição cuidadosamente estruturada entre rivais, com finalidades lucrativas, poderia incrementar dramaticamente a eficiência das organizações públicas. Por outro lado, a ausência de competição poderia anular quaisquer benefícios da privatização. Nessa perspectiva, o que está em causa não é a adoção de um modelo privatizante cujos critérios são pouco claros e conhecidos, mas a necessidade de eficiência aliada à competição. Gostaríamos de questionar aqui os critérios para avaliação da eficiência e da competitividade, tendo em vista o freqüente debate na mídia a respeito dos sistemas elétrico e de telefonia existentes no Brasil.

No que tange aos desligamentos, verificou-se a percepção compartilhada pelo conjunto de entrevistados de que as empresas não definiram critérios que pudessem ser considerados como justos, evidenciado um desrespeito à dignidade dos trabalhadores. Tais critérios poderiam, segundo Caldas (2000), atuar como moderadores dos efeitos negativos decorrentes dos programas de enxugamento implementados.

Quando se pensa na adoção de critérios justos para os desligamentos ou de um posicionamento ético de informar os trabalhadores, cabe questionar se isto é possível no quadro dos programas de enxugamento e privatização implantados em empresas estatais brasileiras. Sem entrar na discussão das implicações para a sociedade como um todo, podemos afirmar que os procedimentos implementados na ELÉTRICA e na TELEFONIA certamente não foram nem justos, nem éticos para com os trabalhadores envolvidos.

\section{Notas}

1 A partir de 2003, com o governo do presidente Luís Inácio da Silva, uma nova administração assume a ELÉTRICA, implementando mudanças na sua gestão.

2 A este respeito ver: Etcheverry (2003), Coutinho e Carbonera (2003), Machado (2001) e Trigo (1999).

3 Refere-se a Fernando Henrique Cardoso, Presidente da República de 1995 a 2001.

4 Fernando Collor de Mello é o primeiro presidente civil eleito no Brasil, após a ditadura militar. Toma posse em março de 1990, iniciando um amplo programa de reforma do Estado, com forte enxugamento da administração pública. Após acusações de corrupção e forte mobilização nacional, o congresso nacional decidiu pelo impedimento do Presidente Collor, que é afastado do cargo em dezembro de 1992.

5 Em pesquisas anteriores ou paralelas aos estudos apresentados no presente artigo, foram também investigados trabalhadores remanescentes aos programas de enxugamento implementados na Elétrica e Telefonia, sendo possível identificar que estes trabalhadores também vivenciam sofrimento psicológico associado às mudanças. Ver Coutinho e Carbonera (2003) e Tolfo, Grandi, Althof, Picinin e Noermberg (2005).

6 A autora investigou ex-trabalhadores de duas grandes empresas estatais, uma delas a ELÉTRICA.

\section{Referências}

Bardin, L. (1977). Análise de conteúdo. Lisboa, Portugal: Edições 70. Caldas, M. P. (2000). Demissão: Causas, efeitos e alternativas para empresa e indivíduo. São Paulo, SP: Atlas.

Correia, F.A.dA. R., \& Moraes, W.F.A. de. (1998, set.). Reestruturação do setor brasileiro de telecomunicações: Aplicação prospectiva do modelo de Porter [CD-ROM]. In Anais do XXIII Encontro Nacional dos Programas de Pós-Graduação em Administração. Foz do Iguaçu, PR: Anpad.

Coutinho, M. C., \& Carbonera, S. T. (2003, 14 out.). Reestruturação em uma empresa pública: Vivências de trabalhadores remanescentes [CD-ROM]. In Anais do VIII Encontro da Associação Nacional de Estudos do Trabalho. São Paulo, SP: ABET/ICT.

Dejours, C. (1999) A banalização da injustiça social. Rio de Janeiro, RJ: Editora da Fundação Getúlio Vargas.

Donahue, J. D. (1992). Privatização: Fins públicos, meios privados. Rio de Janeiro, RJ: Jorge Zahar.

Dutra, J. S., Hipólito, J. A. M., \& Silva, C. M. (2000). Gestão de pessoas por competências: O caso de uma empresa do setor de tele- 
comunicações. Revista de Administração Contemporânea, 4(1), 161-176.

Etcheverry, M. S. (2003, 4 set.). Narrativas nos tempos de reestruturação e flexibilização: Trajetórias de trabalho e empregabilidade de ex-empregados do setor elétrico brasileiro. In XI Congresso Brasileiro de Sociologia. Campinas, SP: Sociedade Brasileira de Sociologia. Retirado em 14 out. 2003, de http://www.sbsociologia. com.br/

Gomes, M. S. E. de A. (2002). Empregabilidade nos tempos de reestruturação e flexibilização: Trajetórias de trabalho e narrativas de ex-empregados do setor elétrico brasileiro. Tese de Doutorado não-publicada, Programa de Pós-Graduação em Ciências Sociais, Universidade Federal do Rio de Janeiro, RJ.

Fischer, T. M. D., Carvalho, E. T., Filho, \& Cavalcanti, F. H. (1998, set.). Estratégias de gestão e reconfiguração organizacional: Os setores de energia elétrica e telecomunicações [CD-ROM]. In Anais do XXII Encontro Anual da Associação Nacional dos Programas de Pós-Graduação em Administração. Foz do Iguaçu, PR: Anpad.

Jesus, J. W. P. de. (1998, set.). A reforma do aparelho de Estado [CDROM]. In Anais do XXII Encontro Anual da Associação Nacional dos Programas de Pós-Graduação em Administração. Foz do Iguaçu, PR: Anpad.

Kovács, I. (2003). Reestruturação empresarial e do emprego. In V. C. Piccinini (Ed.), Caderno de debates: Transformações do trabalho no contexto da reestruturação econômica (pp. 31-44). Porto Alegre, RS: Editora da Universidade Federal do Rio Grande do Sul.

Laranjeira, S. M. G. (1998). Reestruturação no setor de telecomunicações: Aspectos da existência internacional. Revista Latinoamericana de Estúdios del Trabajo, 4(8), 159-178.

Lima, M. E. A. (2000). Violência e reestruturação bancária-o Caso do Banco do Brasil. Saúde Mental e Trabalho, 1, 26-41.

Machado, R. M. X. (2001). Homem em casa vira Maria, aposentadoria e relações conjugais: um estudo de caso em Florianópolis. Dissertação de Mestrado não-publicada, Programa da Pós-Graduação em Psicologia, Universidade Federal de Santa Catarina, Florianópolis, SC

Santos, S. C., \& Reis, M. J. (Eds.). (2002). Memória do setor elétrico da região sul. Florianópolis, SC: Editora da Universidade Federal de Santa Catarina.

Segnini, L. R. P. (2001). Entre o desemprego e a engrenagem do emprego precário [CD-ROM]. In Anais do IV Encontro Regional de Estudos do Trabalho da Associação Brasileira de Estudos do Trabalho. Porto Alegre, RS: ABET.

Seligmann-Silva, E. (1994). Desgaste mental no trabalho dominado. Rio de Janeiro, RJ: Cortez.

Sennet, R. (2002). A corrosão do caráter. Rio de Janeiro, RJ: Record.

Tolfo, S. R., Grandi, C. A., Althof, D. P., Picinin, D., \& Noermberg, T. R. (2005, set.). O processo de reestruturação produtiva de uma empresa de telecomunicações: $\mathrm{O}$ caso dos trabalhadores remanescentes, demitidos e que aderiram ao PDI [CD-ROM]. In Anais do XXIX Encontro Nacional dos Programas de PósGraduação em Administração. Brasília, DF: Anpad.

Trigo, R. A. E. (1999). As transformações do mundo do trabalho: A experiência de uma empresa pública em processo de privatização. Dissertação de Mestrado não-publicada, Programa da Pós-Graduação em Psicologia, Universidade Federal de Santa Catarina, Florianópolis, SC.

Wetzel, U. (2001). Transformação do contrato psicológico no contexto da privatização: Estudo de caso. Revista de Administração Contemporânea, 5, 217-235.

Suzana da Rosa Tolfo é Psicóloga, Mestre e Doutora em Administração. Professora do Curso de Graduação e do Programa de Pós-Graduação em Psicologia e do Curso de Pós-Graduação em Administração da Universidade Federal de Santa Catarina (UFSC). Endereço para correspondência: Departamento de Psicologia, Centro de Filosofia e Ciências Humanas (CFH), UFSC, Campus Universitário, Trindade, Florianópolis, SC, 88040-970. srtolfo@yahoo.com.br

Maria Chalfin Coutinho é Psicóloga, Mestre em Educação pela Universidade Federal do Rio Grande do Sul (UFRGS) e Doutora em Ciências Sociais pela Universidade Estadual de Campinas (Unicamp). Atua como professora junto ao Curso de Graduação e ao

Programa de Pós-Graduação em Psicologia da

Universidade Federal de Santa Catarina (UFSC).

Coordena o Núcleo de Estudos do Trabalho e Constituição do Sujeito (NETCOS), no qual são desenvolvidos projetos de pesquisa e intervenção sobre os sujeitos inseridos no contexto contemporâneo do trabalho. Publicou recentemente o livro "Participação no trabalho" pela editora Casa do Psicólogo. Endereço para correspondência: Rua Deputado Antônio Edu Vieira, 1304, apto 202, Florianópolis, SC, 88040-001. chalfin@mbox1.ufsc.br

\section{Implicações de programas de enxugamento para ex-trabalhadores de empresas estatais}

Suzana da Rosa Tolfo e Maria Chalfin Coutinho

Recebido: 07/08/2006

$1^{a}$ revisão: $19 / 12 / 2006$

Aceite final: 06/03/2007 